\title{
A comparative study between plating \& intramedullary nailing for displaced diaphyseal fractures of radius and ulna in adults
}

\author{
Ambhore $\mathbf{N}^{1}$, Babhulkar $\mathbf{S}^{2}$ \\ ${ }^{1}$ Dr. Nakul Ambhore, D. Ortho, DNB Orthopedics, Sushrut Hospital, Research Centre and Post Graduate Institute of \\ Orthopedics, Ramdaspeth, Nagpur, ${ }^{2}$ Dr. Sudhir Babhulkar, Director \& Chief Orthopedic Surgeon Hospital, Research \\ Centre and Post Graduate Institute of Orthopedics, Ramdaspeth, Nagpur, Maharashtra, India.
}

Corresponding Author: Dr. Nakul Ambhore, C/o Dr Narendra Sangolkar, T7, Laxmikrupa Apartment, Laxmi Nagar, Nagpur, Maharashtra, India, E-Mail: drnakulambhore@gmail.com

\begin{abstract}
Background: In the current era of industrialization and with mechanized farming in India, fractures of forearm bones have become more common. The forearm serves an important role in the functioning of the upper extremity. Hence aggressive management through good anatomical reduction and internal fixation of these fractures has become a necessity. The purpose of this study was to assess and compare functional results of plating and nailing in fracture stabilization. Methods: Retrospective and prospective study with the sample size of 20 patients with both bone forearm fractures. 10 patients were treated with dynamic compression plating and remaining 10 with intramedullary square nails. Results were assessed by time for union, type of fractures, range of motion of elbow and wrist joint, complications and functional assessment were done by Grace- Eversmann Criteria and DASH questionnaire. Results were statistically analysed with Mann- Whitney U-test. Results: Out of 20 cases 18 were males and 2 females, with average age of 38.5 years. 12 fractures were of A32 type according to AO classification. Good or full range of mobility of elbow and wrist joints with excellent $\&$ satisfactory results were present in 16 patients as per Grace-Eversmann criteria. 2 patients showed ulnar nail back out while other 2 had delayed union of fracture, all seen with intramedullary nailing. Conclusion: There was no statistically significant difference between results of nailing and plating. However, it is concluded that while good functional results can be obtained with intramedullary nailing of forearm fractures, open reduction and internal fixation offracture remains the treatment of choice for most forearm fractures with adherence to AO principles.
\end{abstract}

Key Words: Forearm, Fracture, Diaphyses, Internal fixation,Dynamic compressionplate, Intramedullary nailing.

\section{Introduction}

The incidence of diaphyseal fractures of the radius, ulna or both is reported to be approximately 1 to 10 per 10,000 persons per year, although rates may vary according to age and sex. Studies show a bimodal distribution, with the highest incidence among young males aged 10 to 20 years $(10: 10,000)$ and females over age 60years $(5: 10,000)[1,2,3]$. In this era of active life, rapid industrialisation, increasing road traffic accidents, competitive sports; the incidence of fractures of forearm bones are increasing in frequency[4]. Forearm fractures are regarded as articular fractures as slight deviation in the spatial orientation of the radius and ulna significantly decreases the forearm's rotational amplitude and thereby impairs the positioning and function of the hand. Thus, the management of these

\footnotetext{
Manuscript Received: $24^{\text {th }}$ December 2017

Reviewed: $4^{\text {th }}$ January 2018

Author Corrected: $11^{\text {th }}$ January 2018

Accepted for Publication: $16^{\text {th }}$ January 2018
}

fractures and their associated injuries deserve special attention as their treatment is not the same as the treatment of other diaphyseal fractures. Imperfect treatment of fractures of the radius and ulna diaphysis leads to a loss of motion as well as muscle imbalance and poor hand function [5].

Loss of rotation impedes function of the upper limb and activities of daily living [6]. Most of the fractures of both bones of the forearm in adults are treated operatively and various modes of internal fixations are available, the choice of which depends on the treating surgeon[7]. In adults non operative treatment in the form of plaster casting is inadequate to ensure anatomical reduction and healing. Achieving anatomical reduction by close method is difficult and often, maintaining is impossible. Conservative treatment of forearm fracture is fraught with complications of 


\section{Original Research Article}

casting, compartment syndrome, malunion and bayonet apposition [8]. For an optimal result, the basic rule is that a stable anatomical reduction with preservation of adjoining joint mobility must be achieved. Operative treatment is therefore the rule rather than the exception. No matter what the implants are used, the goal is to obtain sound union with excellent functional outcome and early mobilization [7]. The aim of this study is to compare the results of closed intramedullary nailing and open reduction and plate fixation of displaced diaphyaseal fracture radius and ulna in adults and to evaluate the anatomical and functional outcome of both procedures.

\section{Material and Methods}

Study Design: 20 patients with closed displaced diaphyseal fractures of radius and ulna were studied. 10 patients were treated with dynamic compression plating and other 10 with intramedullary square nails. This was a prospective and retrospective study with minimum follow up to one year.

Setting: The following protocol was observed for patients with disphyseal fracture Radius and Ulna

1. General and systemic examination as well as local examination of the patient. It was done in accordance to Acute Trauma Life Support protocol.

2. Vital parameters were recorded. Methodical examination was done to rule out fractures at other sites. Local examination of injured forearm and hand such as attitude and position of the affected upper limb compared with normal counterpart, any abnormal swelling and deformity, their level and direction.

3. Distal vascularity was assessed by radial artery pulsations, capillary filling, pallor and paraesthesia at finger tips.

4. Neurological examination: Sensory system was examined for pain and touch sensation in the radial, ulnar and median nerve innervated areas. Power, including handgrip, was tested in forearm and hand muscles.

5. Movements: Flexion and extension of elbow. Supination, pronation of forearm. Abduction, adduction, palmar flexion and dorsiflexion of the wrist were performed and any restriction of motion and pain observed.

6. Evaluation of patients in terms of:

a) Age, b) Sex, c) Mode of trauma, d) Period between injury and arrival.

7. Musculo-skeletal examination of patient to rule out associated fractures.
8. Stabilization of patient with intravenous fluids, oxygen and blood transfusion as and when required.

9. Primary immobilization of involved limb with above elbow plaster of Paris slab.

10.Radiological assessment: Antero-posterior and truelateral views of injured limb including elbow and wrist joints.

11.Fractures were classified according to $\mathrm{AO}$ classification.

12.Thorough irrigation and lavage of associated compound injuries with hydrogen peroxide and normal saline followed by Povidone Iodine padded dressings.

13.Injection ATS 1500 IU, Injection AGGS 20,000 IU, broad spectrum injectable antibiotics and analgesics were administered for compound injuries of other parts as and when required.

Patient Selection: Patients presenting to the OPD and casualty with history of trauma to forearm and diagnosed as having fracture shaft of radius and ulna on X-ray.

\section{Inclusion Criteria}

1. Patients belonging to age group 18-70 years.

2. Both male and female gender.

3. Diaphyseal fracture of ulna and radius.

4. Patients fit for surgery.

\section{Exclusion criteria}

1. Fracture of forearm bones in children and adolescents.

2. Pathological fractures.

3. Patient unfit for surgery and significant co morbidities affecting bone healing.

4. Patients with associated dislocation or intraarticular extensions.

5. Compound fracture.

Statistical methods-Prospective and retrospective study with minimum follow up to one year for each case.

The patients will be assessed using the GraceEversmann criteria [9] and DASH [10] (Disability of the Arm, Shoulder and hand) questionnaire.Statistical analysis was performed with Mann- Whitney U-test [11] using SPSS 11.5 for Windows software package andp value less than 0.05 was considered significant.

Implants:1)Plating-Dynamic CompressionPlate (DCP)

The plate size was determined depending on the type of fracture that was assessed with the help of X rays. 5 to 7 holed plates were kept for surgery. The cortical screw 
Original Research Article

sizes were also assessed radiologically and made available at the time of surgery.

\section{2) Nailing-Square Nails}

The required nail length was determined by measuring the normal limb. The ulna was measured with a tape from the tip of the olecranon to the ulnar styloid. The radius nail size was difficult to measure clinically and was approximately $2.5 \mathrm{~cm}$ shorter than the ulna. One $\mathrm{cm}$ is subtracted from the measurement to avoid the risk of driving the nail through the end of bone. Nail diameter was determined by measuring the medullary canal size using X-ray. We routinely used $2 \mathrm{~mm}-2.5 \mathrm{~mm}$ diameter nails during the procedures though all sizes were kept available at the time of surgery.

\section{Operative Techniques}

Plating: Dorsal Thompson approach [12] for radius was used in 9 patients with middle \& lower third fractures and Volar Henrys approach [13] for distal third fracture radius was used in 1 patient. Ulna was approached throughout its length by taking linear and longitudinal incision over the subcutaneous border of the ulna.
Nailing: In all cases of intramedullary nailing, radial nail was inserted from the distal end through radial styloid or just lateral to the lister tubercle whereas the nail for ulna was inserted from the olceranon process at a point $5-8 \mathrm{~mm}$ from the dorsal cortex (to avoid entering to trochlear notch) and $5 \mathrm{~mm}$ from the lateral cortex (to compensate for the lateral bow).

Postoperative Management: All patients were immobilised with above elbow slab. In plating group, slab was removed after suture removal while in nailing group it was continued for 6 weeks. Post operative dressing of surgical wound was done on 3rd and 5th day and sutures were removed on 12th day.

IV antibiotics were given for 3 days followed by oral antibiotics for 5 days. Analgesics and anti-inflammatory drugs and other supplements were given.

The patients were followed regularly at monthly interval for first two months then every 6 monthly depending upon the outcome. In each follow up, patients were evaluated radiologically and functionally.

\section{Results}

In this study, maximum age was 70 years and minimum age was 21 years. Mean age was 38.5 years. 18 patients were male. Most common nature of trauma was road traffic accidents as seen in 12 patients, followed by fall on outstretched hand in 5 patients. Right sided extremity was involved in 12 patients. Among 20 radius fractures, 16 were transverse/ short oblique type and 4 were comminuted variety whereas among 20 ulna fractures, 17 were transverse/short oblique type. According AO classification, 12 fractures were of A32, 3of B32, 2fractures are of A31, 2of B31 and 1of fractures are B33. (Table 1)

2 patients had associated injuries like tibia and distal femur fracture. Surgery was performed within $2-3$ days in $70 \%$ of cases, while rest were operated within a week from the day of admission depending on fitness for surgery. All the cases were operated under brachial block and tourniquet control. Mean operation time was 65 minutes (range 40 to $97 \mathrm{~min}$ ) with plate-screw fixation, and 61 minutes (range 35 to $90 \mathrm{~min}$ ) with intramedullary nailing. Complications were reported in 4 patients. 2 patients suffered ulnar nail back out, for which removal of nail and immobilization for 6 weeks in above elbow cast was advised. Other 2 patients showed delayed union. No Patients showed Non union. All the complications were seen to be associated with intramedullary nailing.

The fracture was considered as united when there were no subjective complaints and fracture line was not visible on $\mathrm{x}$ rays. Arbitrarily, those radial and ulnar fractures which healed in less than 6 months were classified as united; those which required more than 6 months to unite and had no additional operative procedure were classified as delayed union and those which failed to unite without another operative procedure were classified as non-union. of 20 patients, 18 patients had sound union in less than 6 months and 2 patients had delayed union. (Table 2) (Figure 1,2,3\&4)

Using the Grace-Eversmann scoring system 16 patients showed excellent results in which fracture union was present and had $>90 \%$ of rotation (Table 3 )

For comparison between two procedures, patients were divided into 2 groups and DASH questionnaire [17] was applied.

Group 1 - patients treated with Plating.

Group 2 - patients treated with Intramedullary Nailing. 
Original Research Article

The mean DASH score was 8.1 (range 5-20) in group 1 and 8.44 (range 5-25) in group 2 indicating no disabilities in both groups. Statistical analysis was performed with Mann- Whitney U-test using SPSS 11.5 for Windows software package.

It was found that there was no statistically significant difference between results of plating and nailing, provided good surgical technique is performed.

Table-1: Type of fracture according to AO classification.

\begin{tabular}{|c|c|}
\hline AO Classification & Number of patients \\
\hline A31 & 2 \\
\hline A32 & 12 \\
\hline B31 & 2 \\
\hline B32 & 3 \\
\hline B33 & 1 \\
\hline Total & $\mathbf{2 0}$ \\
\hline
\end{tabular}

Table-2: Radiological Union

\begin{tabular}{|c|c|}
\hline Bone involved & Duration for union \\
\hline Both Radius \& ulna & 12.33 weeks \\
\hline Only radius & 10.3 weeks \\
\hline Only Ulna & 11.6 weeks \\
\hline
\end{tabular}

On x Ray radiological union of both radius and ulna took 12.33 weeks while radiological union of only radius bone was seen in 10.3 weeks and that of ulna was seen after 11.6 weeks

Table-3: Grace- Eversmann Scoring System.

\begin{tabular}{|c|c|}
\hline Results & Number of Patients \\
\hline Excellent & 16 \\
\hline Good & 2 \\
\hline Acceptable & 2 \\
\hline Unacceptable & 0 \\
\hline
\end{tabular}
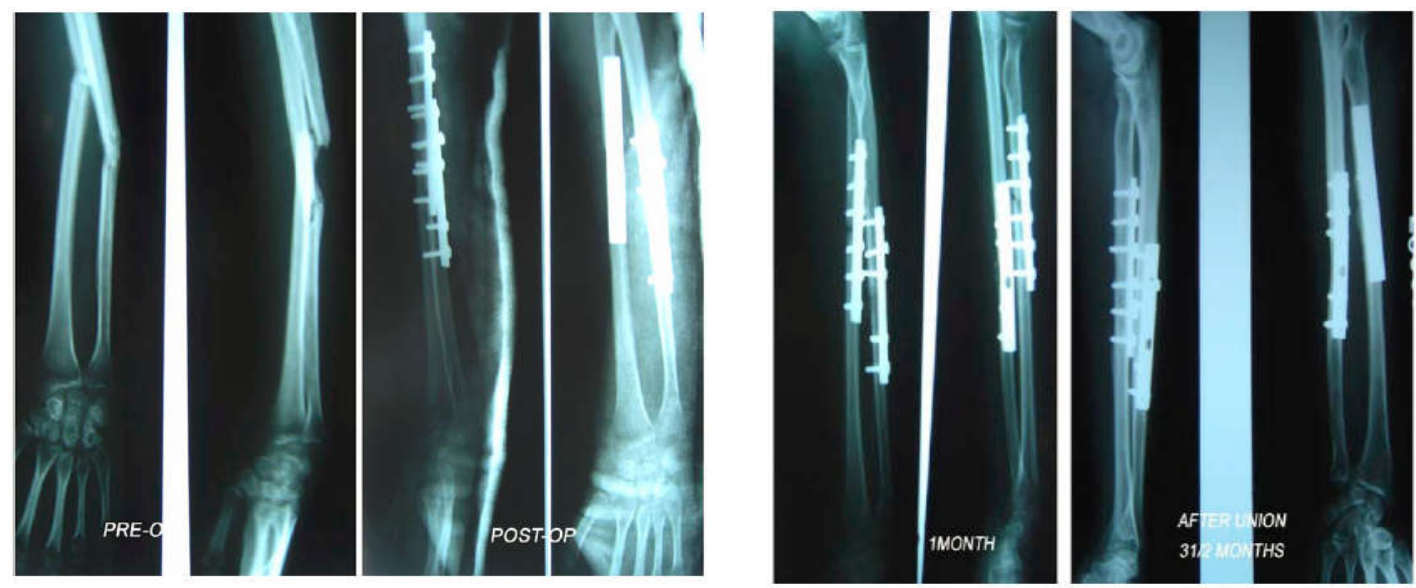

Figure-1: Pre-Op\& Immediate Post Op x rayFigure 2: 1 Month and 3 1/2 Month Follow Up x ray 

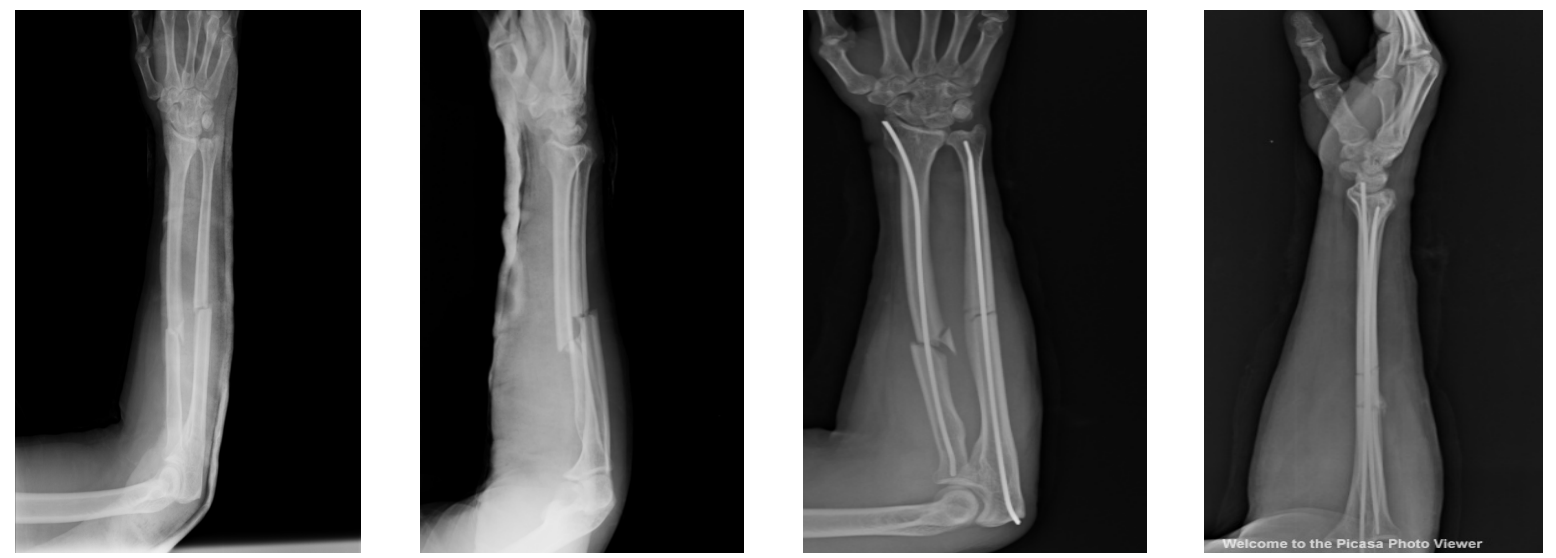

Figure 3: Pre Op \& Immediate Post op x rays Figure 4: Pre Op \& Immediate Post op x rays

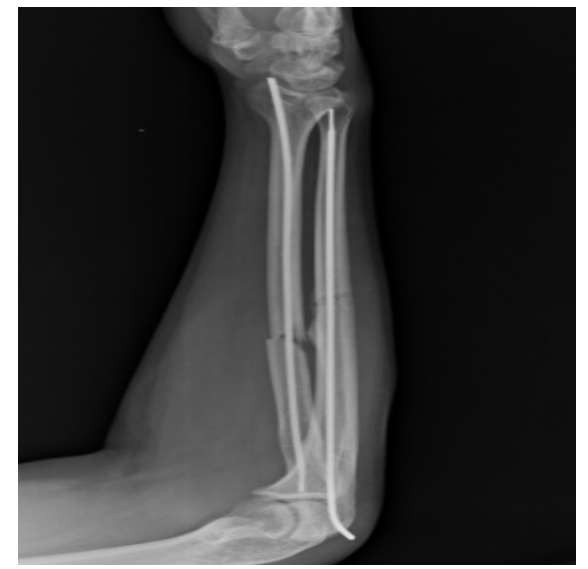

Fig 5: 3 Months flow up ray

\section{Discussion}

The forearm, being a component of upper limb serves important movements that are essential in activities of daily living. The forearmallows pronation and supination, which in turn helps the hand to perform multi axial movements. Fracture of the forearm bones may result in severe loss of function unless adequately treated. Hence good anatomical reduction and internal fixation of these fractures is necessary to restore function.

Treatment of the displaced fracture of shaft of radius and ulna is primarily operative[14]. The use of intramedullary devices to stabilize fracture is not new. Ivory pins, Kuntscher nail, the Rush nail and the Kirschner wire have all been used but all have disappointing results in the form of high rate of non union [15,16,17]. In 1913, Schone first used the silver nails for radius and ulnar medullary fixations [18], and subsequently various nails were developed to stabilized fractures. Vom Saal in 1954 developed first square nail[19]. Mechanically intramedullary nails offer several advantages over the plate and screw fixation.
Intramedullary nails are subjected to smaller bending loads than plates and are least likely to fail by fatigue. The reason is that they are closed to the mechanical axis than usual plate position on the external surface of the bone [20]. Closed intramedullary nailing is minimally invasive procedure requiring shorter operating time. The biology of the fracture healing is not disturbed. Bone grafting is usually not needed and the risk of infection is also minimal[21].

Intramedullary nails act as a load sharing device in fractures with cortical contact. Stress shielding with resultant osteopenia commonly seen with plate and screws is minimised with intramedullary nails. Additional support has to be provided forstabilisation in the form of above elbow slab or castat least for one month and sometimes, in communited fracture, until callus formation seen on subsequent $\mathrm{x}$ ray. This may result into slight stiffness in wrist and elbow joint which can be improved after physiotherapy. In 2016 Tabet A. Al-Sadek stated that open reduction and compression plate fixation have become the treatment of choice for 


\section{Original Research Article}

diaphyseal fractures of forearm bones in adults [22]. Compression-plate fixation gives a high rate of union, low rate of complications and the satisfactory return of rotation of the forearm. Thus, excellent results of this mode of treatment have been reported in many series [23]. The AO- group has reported the successful use of compression plate and screws in the forearm shaft fractures. Since then it is one of the widely used and well-established methods of treating forearm bone fractures $[23,24]$. The advantages of the plate and screw fixation are that the reduction is done under direct vision; the plates are applied so that there is compression at the fracture site. Bone grafting can be done if needed. The fixation being rigid postoperative immobilisation in a cast is not needed.

The disadvantages are the risks of any open surgical fixation, that is increase in chance of infection, disturbance of the soft tissues, periosteal stripping, and evacuation of fracture hematoma [25]. One important disadvantage is the risk of refracture after removal of the compression plate, which necessitates the forearm being protected in a splint for 6 weeks and from severe stress for 6 months [26]. Radius and Ulna are approached separately to avoid extensive soft tissue dissection and resulting complication.

With the use of AO/ASIF $3.5 \mathrm{~mm}$ dynamic compression plate for acute diaphyseal fractures of forearm, rigid and anatomical fixation can be achieved. Distraction forces leading to separation fracture fragments, commonly seen with interlocking nailing procedures for upper limb, is not encountered with DCP. Moreover, radial bowing, that is very important for normal supination and pronation, can be very well maintained with compression plates. Also with DCP fixation, additional post-operative supportive measures may not be required after soft tissue healing and shoulder,elbow and wrist movements can be started early, preventing muscle atrophy and joint stiffness. However, all patients should be curtailed from lifting heavy weights till union of fracture.

The AO principles of internal fixation i.e. anatomical fixation, preservation of vascularity, mechanically stable fixation and rapid mobilization of joints in proximity can be achieved with compression plating system.With anatomical internal fixation, dynamic compression plate is a good fixation for displaced diaphyseal fractures of the forearm bones. Adherence to AO principles, strict asepsis, proper post-operative rehabilitation and patient education are important to obtain good results.
In 2016, Tabet A. Al-Sadek reportedthat radiologicalunion of forearm fractures were found in $100 \%$ in plating group and $86 \%$ in the nailing group. Delayed and non-union results were found in $9 \%$ of patients, all belonging to the nailing group. Average time of union was 9.4 weeks in the plating group and 10.2 weeks in nailing group. They concluded that open reduction and internal fixation with compression plates with strict adherence to surgical technique is the gold standard method of treatment in both bones forearm fractures with excellent results than closed reduction, internal fixation with square nails which is also again a simple method with better results than conservative methods [22].

In 2017 MK Khateeb stated that average surgery time in plating group was 68 minutes and 43 minutes in nailing group. Average union time for radius \& ulna was 7.8 and 8 weeks in nailing group and 9.3 and 9.6 weeks in plating group. There was 1PIN palsy; 2 tourniquet palsy, 1 deep infection, 1 superficial infection, 1 implant failure, no delayed union and 3 non-unions in plating group. In nailing group there were no infection, two delayed union cases and no cases of nail migration. No synostosis, malunion, nail bending or cortical perforation were seen. They concluded that plate osteosynthesis is the implant of choice for all diaphyseal fractures of both bones forearm.

Intramedullary nailing is an attractive alternative. Complication rates are lower as compared to plating, application of above elbow cast after nailing is a drawback of the procedure [27]. In keeping with above mentioned studies, our study supports use of plating over nailing for forearm fracture in view of union, early mobilization, stable and rigid fixation, excellent functional andanatomical results and less complications.

\section{Conclusion}

With rigid/anatomical internal fixation, adherence to AO principles dynamic compression plate is a good fixation for displaced diaphyseal fractures of the forearm bones. Intramedullary nailing of these fractures appears to be technically more challenging and requires more intraoperative radiation than plating and external immobalization is required.

Both modalities of treatment provide equally satisfactory results in treatment of diaphyseal fractures of both bones forearm in adults with same cost effectiveness. Findings of our study are in keeping with the results of above mentioned studies that results of nailing and plating are comparable. 


\section{Original Research Article}

However our study shows that nailing was associated with more post-operative complications as compared to plating and plating provided better compression of fracture site and rigid fixation and hence permitted early mobilization. Also plating group had excellent outcome and satisfaction rate. Our study concluded that plating is a safer and preferable option of forearm bone fractures than nailing. However, long term studies shall be required to confirm these results.

It is with immense pride and a sense of gratitude that I acknowledge the guidance and approbation that I have received from my guide Proff. Sudhir Babhulkar, Director, Sushrut Hospital. I consider it to be my greatest fortune and honour to have been given an opportunity to work under him.

I am highly obligated to Dr. Sushrut Babhulkar, Chief of Joint Replacement Surgery Unit, who initiated this work and by his indefatigable patience and guidance it has come to this level. I express my gratitude to all the people who directly or indirectly helped me to carry out this study. Last but not the least, I express my gratitude to all my patients and their family because of whom this study could be possible.

Conflict of interest: None declared.

Funding: Nil, Permission from IRB: Yes

\section{References}

1. Jónsson B, Bengnér U, Redlund-Johnell I, Johnell O. Forearm fractures in Malmö, Sweden. Changes in the incidence occurring during the 1950s, 1980s and 1990s. Acta Orthop Scand 1999; 70:129. DOI: 10.3109/ 17453679909011249.

2. Bengnér $U$, Johnell $O$. Increasing incidence of forearm fractures. A comparison of epidemiologic patterns 25 years apart. Acta Orthop Scand. 1985 Apr; 56 (2): 158-60.

3. Alffram Pa, Bauer GC. Epidemiology of fractures of the forearm. A biomechanical investigation of bone strength. J Bone Joint Surg Am. 1962 Jan;44-A:105-14.

4. Schmitt KU, Zürich PF, Muser MH, Walz F. Trauma Biomechanics: Accidental injury in traffic and sports. Springer Science \& Business Media, 2009.

5. KB Ravi, TS Raghavendra, S Balasubramanian, Forearm Bone fractures: Dynamic Compression Platting Vs Locking compression plating - Randomised control study. Indian Journal of Basic and Applied Medical Research; June 2014: Vol.-3, Issue- 3, P. 226-232.

6. Goldfarb CA, Ricci WM, Tull F, Ray D, Borrelli J Jr. Functional outcome after fracture of both bones of the forearm.J Bone Joint Surg Br. 2005 Mar;87(3):374-9.

7. Rao MR, Kader E, Sujith SV, Thomas V. Nail-plate combination in management of fracture both bone forearm. J Bone Joint Surg (Br) 2002: 84(B):252-253).

8. Rao R. A prospective study of pediatric forearm bone fractures treated with closed intramedullary square nailing. J. Orthopaedics. 2009;6(1):12-12.

9. Grace TG, Eversmann WW Jr. Forearm fractures: treatment by rigid fixation with early motion.J Bone Joint Surg Am. 1980 Apr;62(3):433-8.

10. Gummesson C, Atroshi I, Ekdahl C. The disabilities of the arm, shoulder and hand (DASH) outcome questionnaire: longitudinal construct validity and measuring self-rated health change after surgery. BMC musculoskeletal disorders. 2003 Jun 16;4(1):11.

11.McKnight PE, Najab J.Mann-Whitney UTest. Corsini Encyclopedia of Psychology. 2010.DOI: 10. 1002/ 9780470479216. corpsy0524.

12. Thompson JE. Anatomical methods of approach in operations on the long bones of the extremities. Annals of surgery. 1918 Sep;68(3):309.

13. Henry MH, Griggs SM, Levaro F, Clifton J, Masson MV. Volar approach to dorsal displaced fractures of the distal radius. Techniques in hand \& upper extremity surgery. 2001 Mar 1;5(1):31-41.

14. Anderson LD, Sisk D, Tooms RE, Park WI 3rd.Compression-plate fixation in acute diaphyseal fractures of the radius and ulna.J Bone Joint Surg Am. 1975 Apr;57(3):287-97.

15. Sage, F.P. Medullary fixation of fractures of the forearm. A study of the medullary canal of the radius and a report of 50 fractures of the radius treated with a prebent triangular nail. J Bone Joint Surg Am. 1959 December;41:1489-1516.

16. Crenshaw AH, Zinar DM, Pickering RM. Intramedullary nailing of forearm fractures.Instr Course Lect. 2002;51:279-89. 


\section{Original Research Article}

17. Gadegone W, Salphale YS, Lokhande V.Screw elastic intramedullary nail for the management of adult forearm fractures.Indian J Orthop.2012 Jan;46(1):65-70. doi: 10.4103/0019-5413.91637.

18. Schone G. Zurbehandulung von vorderarmfrakturenmitbolzung. Munch Med Wochenschr. 1913;60: 2327-8.

19. VomSaal F. (1954): quoted by Marek F. M. 1961.

20. Lee YH, Lee SK, Chung MS, Baek GH, Gong HS, Kim KH. Interlocking contoured intramedullary nail fixation for selected diaphyseal fractures of the forearm in adults.J Bone Joint Surg Am. 2008 Sep;90(9):1891-8. doi: 10.2106/JBJS.G.01636.

21. Amit Y, Salai M, Chechik A, Blankstein A, Horoszowski H. Closing intramedullary nailing for the treatment of diaphyseal forearm fractures in adolescence: a preliminary report. Journal of Pediatric Orthopaedics. 1985;5 (2): 143.

22. Al-Sadek TA, Niklev D, Al-Sadek A. Diaphyseal Fractures of the Forearm in Adults, Plating Or Intramedullary Nailing Is a Better Option for the Treatment?.Open access Macedonian journal of medical sciences. 2016 Dec 15;4(4):670. http://doi.org/ 10. 3889 /oamjms. 2016.138.
23. Müller ME, Allgöwer M, Perren SM. Manual of internal fixation: techniques recommended by the AOASIF group. Springer Science \& Business Media, 1991. https://doi.org/10.1007/978-3-662-02695- 3.

24. Vander Griend R, Tomasin J, Ward EF.Open reduction and internal fixation of humeral shaft fractures. Results using AO plating techniques.J Bone Joint Surg Am. 1986 Mar;68(3):430-3.

25. Arora R, Lutz M, Hennerbichler A, Krappinger D, Espen D, Gabl M.Complications following internal fixation of unstable distal radius fracture with a palmar locking-plate. J Orthop Trauma.2007 May; 21 (5): 316-22.

26. Deluca PA, Lindsey RW, Ruwe PA. Refracture of bones of the forearm after the removal of compression plates. J Bone Joint Surg Am. 1988; 70(9):1372-6. https://doi.org/10.2106/00004623-198870090-00015 PMid : 3182889.

27. Khateeb MK, Akbar MN. Comparison of Intramedullary Nailing to Plating for Both-bone Forearm Fractures in Adult. Indian Journal of OrthopaedicsSurgery.2017;3(2):135-42.DOI: 10.18231/ 2395-1362.2017.0027

\section{How to cite this article?}

Ambhore N, Babhulkar S. A comparative study between plating \& intramedullary nailing for displaced diaphyseal fractures of radius and ulna in adults. Surgical Update: Int J surg Orthopedics.2018;4(1):29-36.doi:10. 17511/ijoso.2018.i01.06. 